\title{
CARACTERÍSTICAS DO RELACIONAMENTO CONJUGAL DE CASAIS QUE OPTARAM POR NÃO TER FILHOS
}

\author{
RELATIONSHIP CHARACTERISTICS OF COUPLES \\ WHO CHOOSE NOT TO HAVE CHILDREN
}

CARACTERÍSTICAS DE LA RELACIÓN DE PAREJA QUE ELIGIÓ NO TENER HIJOS

INGRID MESQUITA COELHO ${ }^{1}$

\section{DANIEL CERDEIRA DE SOUZA ${ }^{2}$}

\section{IOLETE RIBEIRO} DA SILVA

${ }^{1}$ Universidade Federal do Pará, Belém/PA, Brasill

2 Universidade Federal de Santa Catarina, Florianópolis/SC, Brasil

${ }^{3}$ Universidade Federal do Amazonas, Manaus/AM, Brasil

Recebido em 22/03/2020

Aprovado em 17/06/2020
RESUMO: Nesta pesquisa tivemos como objetivo descrever características do relacionamento conjugal de casais sem filhos por opção, elencando as razões que os levaram a optarem por tal decisão e compreender seu nível de satisfação no que concerne ao seu relacionamento conjugal por meio de uma pesquisa qualitativa de cunho exploratório. Participaram 10 casais, sendo cinco casais adultos jovens (18 a 30 anos) e cinco casais adultos (31 a 60 anos). A coleta de dados foi realizada por meio de um formulário on-line e os dados foram analisados a partir da análise de conteúdo proposta por Bardin. Os resultados foram compilados em quatro categorias que mostraram as dinâmicas envolvidas no desejo de não ter filhos, sendo: (a) Falta de desejo de ter filhos; (b) Desenvolvimento da carreira profissional; (c) A responsabilidade exigida para a criação de um filho; (d) Estabilidade financeira. Por fim, demonstramos que os casais estavam satisfeitos com seus relacionamentos e que enfrentavam alguns estigmas baseados em gênero por conta da decisão da não maternidade/paternidade.

Palavras-chave: Conjugalidade; Família; Filhos; Maternidade; Paternidade.

ABSTRACT: This research aimed to describe characteristics of the marital relationship of couples without children by choice, listing the reasons that led them to make this decision and to understand their level of satisfaction concerning their marital relationship through exploratory and qualitative research Ten couples participated, five young adults (18 to 30 years old) and five adults (31 to 60 years old). Data collection was performed using an online form and was analyzed using the content analysis proposed by Bardin. The results are grouped into four categories that show the dynamics involved in the desire not to have children: (a) Lack of desire to have children; (b) Professional career development; (c) The responsibility required for raising a child; (d) financial stability. Finally, the study showed that couples were satisfied with their relationships and that faced some stigmas based on gender due to the decision of non-maternity / paternity.

Keywords: Conjugality; Family; Children; Maternity; Paternity.

RESUMEN: Esta investigación tuvo como objetivo describir las características de la relación conyugal de parejas sin hijos por elección, comenzando como razones que los llevaron a elegir tal decisión y a comprender su nivel de satisfacción que no se refiere a su relación conyugal a través de una investigación cualitativa. exploratorio Participaron diez parejas, cinco parejas jóvenes (de 18 a 30 años) y cinco parejas adultas (de 31 a 60 años). La recopilación de datos se realizó mediante un formulario en línea y los datos se analizaron mediante el análisis de contenido propuesto por Bardin. Los resultados se compilaron en cuatro categorías que muestran cómo se usa la dinámica en el deseo de no tener hijos, siendo: (a) Falta de deseo de tener hijos; (b) Desarrollo profesional profesional; (c) La responsabilidad requerida para criar a un niño; (d) estabilidad financiera. Finalmente, el estudio demostróque las parejas estaban satisfechas con sus sentimientos y que tenían algunos estigmas asociados con el género debido a la decisión de no maternidad / paternidad.

Palabras clave: Conyugalidad; Familia; Niños; Maternidad; Paternidad. 


\section{INTRODUÇÃO}

A contemporaneidade traz em seu bojo o reconhecimento social e legislativo de novas configurações familiares, ressignificações nos conceitos de maternidade e paternidade e nas relações de gênero. A família era concebida unicamente por um prisma tradicional, alicerçado na heteronormatividade, porém o cenário atual é constituído por diversas formas de ser família, sendo monoparental, homoparental, reconstruída etc. Diante desse cenário encontram-se os casais voluntariamente sem filhos.

As configurações de união conjugal sofreram mudanças ao longo dos séculos. A esse respeito, Priore (2014) afirma que entre os séculos XIV e XX, na Europa, os casados desenvolviam, de maneira geral, tarefas específicas. Cada qual tinha um papel a desempenhar diante do outro baseado nos estereótipos de gênero. Os maridos deveriam se mostrar dominantes, voluntários no exercício da vontade patriarcal, insensíveis e egoístas. As mulheres, por sua vez, apresentavam-se como fiéis, submissas, recolhidas e sua tarefa mais importante era a procriação. A autora argumenta que os homens as tratavam como "máquina de fazer filhos" por serem herdeiras direta de Eva, responsável pela expulsão do paraíso e pela queda dos homens e, para pagar pelo seu pecado, teriam que dar à luz em dores. Dessa forma, a configuração familiar dominante no ocidente tem origem na concepção judaicocristã de família, sendo monogâmica e heterossexual, onde a mulher deve ser submissa ao homem.

Mas com diversas transformações históricas do passar do tempo, as diversas formas de conjugalidade vêm recebendo cada vez mais visibilidade e, assim, podemos refletir que a união conjugal pode não mais significar necessariamente a chegada da maternidade/paternidade, havendo uma separação entre expectativas conjugais, parentais e sexuais entre os parceiros, uma vez que o casal pode optar por não ter filhos.

No Brasil o número de casais sem filhos vem aumentando significativamente. Dados do IBGE (2015) apontam que, entre 2002 e 2012, reduziram os arranjos familiares constituídos por casal com filhos (52,7\% para 45\%). Em dez anos, o indicador recuou 18,6\%, chegando a 1,74 filho por mulher em 2014. Com a redução, ganha importância o número de casais sem filhos. Os números apresentados na Síntese de Indicadores Sociais do IBGE de 2015 apontam um avanço de 14\% para 19,9\%, em 2014.

Percebemos que o Brasil passa por uma acentuada transição demográfica, apresentando um número significativo de casais sem filhos. Esse fenômeno abre um novo e rico campo de pesquisa. Segundo Caetano, Martins, e Motta (2016), as pesquisas apontam que, além da exclusão social, o casal sem filhos sofre olhares de desprezo ou descrença. Os dados da pesquisa oferecem uma dimensão dos prejuízos sociais enfrentados, especialmente por mulheres que podem ser rotuladas de: "anormais", "loucas", "más", entre outros. Parece que o que se aponta aqui é que o reconhecimento de novos modelos de configurações familiares e das mudanças nas expectativas e divisão de tarefas conjugais (pela legislação e pelas teorias) não acompanha o mesmo ritmo na cultura e nas relações sociais. Diante destas reflexões iniciais, objetivamos, neste estudo, descrever as características do relacionameto conjugal de casais que optaram por não ter filhos e como essa decisão influencia a satisfação conjugal. 


\section{CONJUGALIDADE}

A decisão voluntária de casais por não ter filhos foi propiciada por diversas transformações ao longo da história. Uma dessas transformações refere-se ao casamento e os seus significados. Antes engessado em padrões "moralistas" e ditos tradicionais, hoje o casamento ganha novos contornos, assim como o conceito de conjugalidade. A formação da conjugalidade, na visão sistêmica, segundo FéresCarneiro (1998) e Féres-Carneiro \& Diniz-Neto (2010), é um processo complexo, que vai para além do reconhecimento estatal da união entre pessoas (o casamento civil), envolvendo diversos níveis do relacionamento e contextos que resultam na definição psicossocial de uma relação afetiva estável. Autores de estudos sobre família e casamento, como Berger e Kellner (1964) e Grandesso (2000), abordam a conjugalidade como um processo de construção de uma realidade comum. Dessa forma, cada parceiro, ao entrar em um relacionamento, experimenta uma reconstrução de sua realidade individual, criando referências comuns e uma identidade conjugal.

É através da convivência que os casais buscam a satisfação e a qualidade na relação. Cada cônjuge, ao se engajar na relação a dois, experimentaria uma reconstrução de sua identidade (Féres-Carneiro \& Diniz-Neto, 2010). Dessa forma, os relacionamentos íntimos assumem aspecto central da vida adulta e a qualidade dos mesmos tem implicações não só na saúde mental, mas também na saúde física e vida profissional de homens e mulheres (Norgren et al., 2004).

Concernente à satisfação conjungal, um ponto relevante a se discutir refere-se à paternidade/maternidade, visto que essa nova fase produz transformações na dinâmica do casal e, consequentemente, na experiência da conjugalidade. A esse respeito, Magagnin et al. (2003) afirmam que a transição da conjugalidade para a parentalidade é o período do ciclo familiar em que o investimento dos parceiros é transferido para a relação com os filhos. O autor defende que casais com filhos, quando a chegada destes for um processo bem organizado, conseguem produzir um ajustamento dos comportamentos e sua consequente satisfação.

Apesar de a literatura abordar de forma mais significativa a conjugalidade de casais com filhos, é possível encontrar autores que se propõem a discutir a conjugalidade de casais sem filhos. A exemplo disso, Rios e Gomes (2009) realizaram uma pesquisa qualitativa com 4 (quatro) casais sem filhos por opção, e, na totalidade dos casais entrevistados, as autoras observaram que a conjugalidade desses casais apresentava características contemporâneas, ou seja, homens e mulheres estão envolvidos com o desenvolvimento profissional, dividem as tarefas domésticas igualitariamente, ligam-se a um estilo de vida essencialmente adulto, buscam a satisfação afetiva na relação com o outro e, no geral, o projeto compartilhado associa-se ao cuidado pelo outro ou ao aprimoramento profissional e intelectual.

Somers (1993) comparou casais sem filhos por opção com casais com filhos. Participaram do estudo 74 pessoas "voluntariamente sem filhos" e 127 com filhos. $\mathrm{O}$ autor constatou que os casais sem filhos apresentaram maiores índices de ajustamento conjugal e maiores níveis de coesão e satisfação diádica quando comparados àqueles com filhos. 
MITO DO AMOR MATERNO, REPRODUÇÃO E CASAMENTO

Como resultado dos estereótipos de gênero, a maternidade é pensada como função feminina por excelência, concernente à natureza da mulher e seu destino biológico, sendo o amor materno um dos mais puros e idealizados. Essa exaltação ao amor materno é relativamente recente dentro da história da civilização ocidental e, mesmo sendo descrito como instintivo e natural, constitui-se em um mito construído pelos discursos filosóficos, médicos e políticos a partir do século XVIII (Moura \& Araújo, 2004).

Elisabeth Badinter (1985), em seu livro Um amor conquistado: o mito do amor materno, discute que o relacionamento afetivo, mãe e bebê, não é natural, mas construído. Para validar essa afirmação, Badinter discorre sobre a concepção do amor materno ao longo dos séculos. De acordo com a autora, no século XVIII as mulheres recusavam-se a amamentar, sendo uma prática exercida por amas de leite. Essa rejeição tinha diversas explicações, entre elas: não desgastar o corpo; o desapego pela criança; ausência de tempo; desinteresse do marido pela esposa. Ainda de acordo com a autora, as mulheres eram estimuladas a evitar atos de ternura, pois esse sentimento poderia fazer com que os jovens adquirissem vícios. Assim, para garantir a criação de bons filhos, a mãe deveria instigá-los pelo terror, repreensões, castigos e lamentos.

Segundo Badinter (1985), somente a partir de 1760 a figura da mãe passa a ter importância nos cuidados dos seus filhos e o amor materno passa a ser valorizado e glorificado como grandeza natural e valor social para a sociedade.

Após 1760, abundam as publicações que recomendam às mães cuidar pessoalmente dos filhos e lhes "ordenam" amamentá-los. Elas impõem à mulher a obrigação de ser mãe antes de tudo, e engendram o mito que continuará bem vivo duzentos anos mais tarde: o do instinto materno, ou do amor espontâneo de toda mãe pelo filho (Badinter, 1985, p. 121).

Diante disso, a criação dos filhos pela própria mãe passa a ser valorizada. A falta de amor é, portanto, considerada como um crime imperdoável. A mãe que não experimenta tal sentimento é marginalizada, pois teria perdido sua especificidade feminina (Badinter, 1985). Instaura-se, portando, o mito do amor materno. Tal mito restringe a mulher ao destino certo de ser mãe, afinal, é "natural", a mulher "nasceu" para isso e o casamento então cumpriria o dever sagrado de perpetuação da espécie e assim perduraria até o século XX, quando o casamento como sinônimo de procriação começou a sofrer rachaduras nos anos 1960 com o advento da pílula anticoncepcional.

Segundo Priore (2014), ao impedir a ovulação, a milagrosa droga fazia com que as mulheres não concebessem. Em 1960 foi autorizada sua venda no mercado americano. De acordo com a autora, as mulheres, por intermédio dos movimentos feministas, começaram a lutar por direitos, dentre eles, a contracepção. Na década de 70, a Lei Neuwirth descriminalizou a prática nos EUA. A partir de então, qualquer mulher, munida de receita médica, podia comprar pílulas anticoncepcionais. Foi uma espécie de revolução.

Dessa forma, é observado que a partir dos anos 1960 fortaleceu-se o movimento por busca pela liberdade reprodutiva, interpretado e proposto como caminho para alcançar a almejada igualdade de gênero. Dentro dessa filosofia destaca-se Simone de Beauvoir (1980), que explorou a alienação e a subalternidade das mulheres. Ao expor a questão, contestou o estereótipo de gênero do "destino biológico" da mulher, questionou-se a responsabilidade exclusiva das mulheres mães pela criação dos filhos e, também, o mito do amor "instintivo", deixando claro que a mulher é 
um ser humano dotado de diversos sentimentos, como a frustração e indignação, que muitas vezes não estão ligados à sua chamada "função específica e natural" (Caetano, Martins, \& Motta, 2016).

\section{METODOLOGIA}

Para o alcance dos objetivos propostos, foi adotada a abordagem qualitativa com a representação numérica, mas com a compreensão profunda do grupo social proposto a ser investigado, buscando maior familiaridade com o problema, com vistas a torná-lo mais explícito ou a construir hipóteses (Gil, 2017).

$\mathrm{Na}$ busca de atingir os objetivos, inicialmente estipulamos a participação na pesquisa de casais sem filhos por opção em três faixas etárias distintas. A primeira refere-se a adultos jovens de 18 a 30 trinta anos; a segunda refere-se a adultos de 31 a 60 anos e a terceira refere-se a casais a partir dos 60 , porém não foram encontrados casais na terceira faixa.

Acreditamos que o fato de pessoas acima de 60 anos se encontrarem em menor número nas redes sociais, que foram os instrumentos de divulgação da pesquisa, dificultou o acesso a essas pessoas. Segundo o IBGE (2017), apesar de ser o grupo que mais cresceu, os usuários com mais de sessenta anos ainda são o menor grupo etário de usuários conectados se comparado à quantidade total da população de pessoas deste grupo, com apenas $31,1 \%$ de toda a população idosa do país conectada na internet.

A ausência de participantes a partir dos sessenta anos de idade pode estar associada ao fato de os padrões de família tradicional serem ainda mais rígidos há algumas décadas, logo, desviar desses padrões tinha um peso expressivamente maior. De acordo com o IBGE (2018), o número de filhos caiu nas ultimas três décadas de 6,28 para 1,7 .

Foram excluídos casais que optaram por não ter filhos, mas que tinham filhos de outros relacionamentos, casais que biologicamente não podem ter filhos e casais que optaram por não ter filhos no momento, mas que ainda pretendem tê-los, casais em que um ou ambos os cônjuges tenha idade inferior a 18 anos, um dos cônjuges ou ambos os cônjuges solicitassem que seus dados fossem retirados da pesquisa.

A pesquisa não restringiu os critérios de seleção dos participantes a características sociais, econômicas e culturais específicas. Seguindo essa linha de pensamento, não foram colocadas restrições quanto a uma região, estado ou município. Também é importante enfatizar que a pesquisa não se limitou somente a casais heterossexuais, visto que casais homossexuais também podem optar pela não paternidade/ maternidade.

A divulgação da pesquisa ocorreu por meio das redes sociais Facebook e Instagram. Os interessados entraram em contato com a pesquisadora de forma online e a estes foram apresentados os objetivos da pesquisa, bem como o link do formulário. Os mesmos foram orientados a responder o questionário de forma individual e sem a interferência do cônjuge. Participou um total de dez casais (20 participantes no total), sendo oito casais heterossexuais e dois casais homossexuais.

A participação na pesquisa esteve condicionada à marcação de ciência do TCLE, descrito no formulário on-line. Com o acesso crescente à internet em todo o mundo, as pesquisas com o uso do ambiente virtual mostram-se como uma tendência atual para a coleta de dados. Embora os grupos etários mais jovens continuem a ter a maior taxa de uso da internet, a adesão de pessoas de faixas etárias mais avançadas a esta ferramenta tem aumentando nos últimos anos. Dessa maneira, a utilização da internet 
como recurso auxiliar de troca e disseminação de informações possibilita a melhoria e a agilidade do processo de pesquisa, além de permitir ao pesquisador o contato rápido e preciso com os indivíduos participantes do estudo (Faleiros et al., 2016).

O formulário on-line foi composto por três seções com por questões estruturadas e semiestruturadas. A primeira seção referiu-se à identificação dos participantes (idade, sexo, tempo do relacionamento conjugal, ocupação, moradia, escolaridade e renda familiar); a segunda seção referiu-se à investigação das razões apontadas pelos cônjuges para não ter filhos e a terceira seção referiu-se à descrição do grau de satisfação que os casais sentem referente ao seu relacionamento conjugal, onde foi aberto um espaço para que o cônjuge discorresse sobre aspectos relevantes do seu relacionamento conjugal.

A análise das seções do material qualitativo deu-se por meio da análise de conteúdo de Bardin (2016), realizada em três etapas: (a) Pré-análise; (b) Exploração do Material e (c) Tratamento dos Resultados, Inferência e Interpretação.

A pré-análise consiste na leitura flutuante, constituição de corpus e preparação do material a ser analisado. Neste estudo, os dados da pesquisa foram constituídos pela coleta on-line. $\mathrm{Na}$ análise do material, foi realizada a exploração dos dados produzidos na pesquisa, buscando pistas que auxiliassem nas respostas dos objetivos do estudo. Por fim, o tratamento dos resultados é a fase da reflexão, da intuição por meio de embasamento nos materiais empíricos, onde o conhecimento acumulado é debatido com o conhecimento adquirido, recortado por meio de palavras, frase ou parágrafo. Os dados foram tratados em busca de interpretações guiadas pelos objetivos propostos. A partir dos dados explorados, foram realizadas interpretações e discussões, tomando-se como referencial teórico pertinente ao objetivo deste estudo (Bardin, 2016).

Este projeto de pesquisa foi submetido ao Comitê de Ética em Pesquisa da Universidade Federal do Amazonas em 17/04/2018, tendo sido registrado pelo CAEE n. 88674618.4.0000.5020. Na pesquisa seguimos as diretrizes das Resoluções n. 466/212 e n. 510/2016 do Conselho Nacional de Saúde, que assegura toda sua integridade e compromisso com as questões éticas em pesquisas envolvendo seres humanos. Ressaltamos que a pesquisa foi financiada pela CAPES no formato de uma bolsa de iniciação científica e uma bolsa de mestrado. Utilizamos o Termo de Consentimento Livre Esclarecido - TCLE como forma de receber autorização dos sujeitos participantes da pesquisa.

\section{RESULTADOS E DISCUSSÕES}

\section{Perfil dos casais sem filhos por opção}

Os dados coletados permitiram traçar alguns aspectos do perfil dos casais sem filhos por opção. Das vinte pessoas entrevistadas, 10 possuem ensino superior completo, oito possuem ensino superior incompleto e duas possuem ensino médio completo. Esses dados sugerem que a decisão por não ter filhos pode estar associada ao grau de instrução. A Pesquisa Nacional por Amostra de Domicílios (Pnad) de 2009 (IBGE, 2009), por meio da Síntese de Indicadores Sociais, mostra que a taxa de fecundidade está caindo no Brasil nas últimas décadas e relaciona o índice com o nível de instrução das mães (IBGE, 2010). De Ollos e Kapinus (2002) enfatizam ainda mais essa relação ao afirmarem que as pessoas que optaram por não ter filhos têm a predisposição a um grau de instrução mais elevado. 
No que tange à renda, dois casais possuíam renda de até 2 (dois) salários mínimos, cinco casais de 4 (quatro) a 10 salários mínimos, dois de 10 a 20 salários mínimos e um casal possuía renda acima de 20 salários mínimos. Desta forma, os dados sugerem que oito casais possuem renda de no mínimo 4 (quatro) a 10 salários mínimos, indicando que a decisão pode ser mais comum em pessoas com condições financeiras mais altas e estáveis que a média populacional brasileira.

\section{A decisão por não ter filhos}

A partir da análise do conteúdo dos dados, organizamos quatro categorias: falta de desejo, desenvolvimento da carreira profissional, a responsabilidade exigida para a criação de um filho, estabilidade financeira.

\section{Falta de desejo pela maternidade/paternidade}

A falta de desejo pela maternidade/paternidade é apontada por sete participantes como motivo para não terem filhos, apesar de os mesmos argumentarem outros fatores para a decisão. Foi observado que as respostas dadas por mulheres demostravam culpabilidade pela ausência do desejo de serem mães.

... já cheguei a pensar que tinha algo errado comigo, porque só eu não queria ser mãe. (mulher, 24 anos, acadêmica de Nutrição)

... acho diferente não querer ser mãe, mas o que posso fazer se não tenho desejo? Não quero ter para suprir o desejo das pessoas, não são eles que irão criar (mulher, 36 anos, internacionalista)

A culpa descrita pode estar associada ao fato de a decisão desviar daquilo que é tido como "normal" dentro da sociedade por conta do mito do amor materno (Badinter, 1985) aliado à noção de norma de procriação da conjugalidade (Priore, 2014). Além disso, pode se relacionar com as expectativas de gênero feminino, que teria como norma a maternidade compulsória para mulheres (Mattar \& Diniz, 2012).

\section{Carreira profissional}

No que concerne a respostas relacionadas ao desenvolvimento profissional como motivo para a tomada da decisão por não ter filhos, estas foram dadas por mulheres entrevistadas. Os homens não apresentaram respostas relacionadas a esse aspecto.

... muitas mães conciliam carreira profissional e a maternidade, mas eu não vejo como poderia ter alcançado meu sonho como profissional se eu tivesse filhos [...] eu fiz uma escolha e escolhi minha carreira. (mulher, 41 anos, ondontóloga)

... meu esposo não ficaria em casa cuidando da criança, essa seria uma responsabilidade minha [...] minha vida iria parar [...] eu lutei muito para chegar onde estou, não quero deixar os meus sonhos para ser mãe. (mulher, 36 anos, internacionalista) 
O fato de a carreira profissional estar presente como argumento para a não maternidade na maioria das mulheres entrevistadas e não ser citado pelos homens pode estar relacionado aos estereótipos de gênero, onde a mãe tem quase por completo a responsabilidade pela criação dos filhos e é cobrada socialmente para executar esse papel como prioridade na sua vida, enquanto que os homens não sofrem essas cobranças tanto quanto as mulheres. Logo, devido às desigualdades de gênero, o impacto na carreira profissional dos pais é menos significativo do que o impacto na carreira das mães.

Essa perspectiva está em concordância com os estudos de Heilman e Okimoto (2008), que investigaram os efeitos da maternidade no mercado de trabalho. Os autores utilizaram a perspectiva de gênero para comparar 100 estudantes de MBA, homens e mulheres, com filhos e sem filhos, que já se encontravam ativamente no mercado de trabalho. Os resultados do estudo mostraram que tanto a paternidade quanto a maternidade têm impacto negativo, mas ser mãe tem um impacto negativo maior, pois o status materno pode impedir o progresso na carreira.

Quando se trata de investimento na carreira, maternidade e paternidade têm resultados opostos, como indicou o estudo de Hewlett (2002): em um recorte da pesquisa internacional a respeito da vida profissional e privada de mulheres e homens altamente qualificados, um dos resultados do estudo mostrou que, quanto mais bem-sucedido o homem, mais provavelmente irá encontrar uma esposa e tornar-se um pai. Já $49 \%$ das mulheres, principalmente as que a pesquisadora nomeia como ultraempreendedoras, ou seja, com remuneração acima de US\$ 100.000 por ano, não têm filhos, e 75\% dos homens têm. Tal resultado pode indicar que, para além dos desafios da carreira, as mulheres têm um desafio maior com a maternidade, como a dupla ou tripla jornada de trabalho.

\section{Responsabilidade para criar filhos}

A responsabilidade de criar um filho foi apontada por cinco das mulheres entrevistadas.

... ser mãe significa ter uma alta carga de responsabilidade, não é que eu não me ache capaz de criar uma criança, mas eu não desejo ter essa responsabilidade, talvez seja egoísmo da minha parte. (mulher, 29 anos, dona de casa)

... como em sã consciência eu iria abrir mão de tudo que tenho e conquistei para me dedicar à maternidade? Já tenho muitas responsabilidades enquanto filha, profissional e esposa. Só de pensar em acordar ainda mais cedo, levar para escola, limpar a fralda e educar. (mulher, 52 anos, enfermeira)

... eu não preciso disso. As pessoas idealizam a maternidade, mas a verdade é que ser mãe significa estar sempre disposta a abrir mão. (mulher, 27 anos, acadêmica de Psicologia)

Apenas as mulheres elencaram a responsabilidade pela criação do filho como motivo para a não maternidade. Essa preocupação pode emergir mais em mulheres devido à criação dos filhos estar associada à figura materna. Essa vinculação vem sofrendo rachaduras ao longo dos anos, mas ainda é uma realidade dentro dos padrões de maternidades vigentes. Resultados parcialmente semelhantes foram encontrados em um estudo brasileiro sobre as representações de maternidade em mulheres não 
mães (Patias \& Buaes, 2012). Nesse estudo, a questão da impossibilidade de realizar projetos futuros em função da responsabilidade de cuidar de um filho foi apontada como um fator importante na decisão de não tê-los.

\section{Estabilidade financeira}

A estabilidade financeira é apontada como motivo para não ter filhos por oito participantes (seis homens e duas mulheres). Esses dados corroboram os resultados obtidos nas pesquisas de Borges (2013); Levandowski e Piccinini (2006) e Santos (2015). Os autores constataram que a perspectiva de proporcionar melhor suporte aos filhos (alimentação, saúde, escolaridade, lazer e outros) por meio de uma renda maior é um forte influenciador para a constituição familiar tardia, menos numerosa e até mesmo sem filhos para casais contemporâneos, que passam a adiar o momento da maternidade/paternidade ou abdicar o aumento da família.

Caetano, Martins, e Mota (2016), em busca de compreender a não maternidade/ paternidade, citam como uma das causas que levam a essa decisão as preocupações relacionadas ao bem-estar da criança e envolvendo espcialmente estabilidade financeira. Assim, casais - por acreditarem não possuir condições financeiras "adequadas" para se ter um filho - podem optar por não tê-lo, o que também aparece relatado nos dados da pesquisa:

Ter filhos é muito caro e eu não possuo condições pra isso. (homem, 26 anos, frentista)

A fala pode nos levar à reflexão do esteriótipo de gênero do homem como provedor da subsistência do lar. Ser provedor é uma das características masculinas esperadas no desempenho da dinâmica conjugal e tem especial preocupação no exercício da paternidade (Freitas et al., 2009).

Aqui parece uma contradição nos resultados. O perfil dos entrevistados citado anteriormente mostra que a maioria dos casais que optou por não ter filhos é estável e tem condição financeira elevada que, de acordo com a literatura, favoreceria melhores condições para ter filhos. A respeito disso, consideramos o fato de que, ao contrário da época que os filhos eram um investimento, ou seja, força de trabalho agrícola, hoje os filhos deixaram de ser um investimento lucrativo e passaram a ser um investimento caro. Dessa forma, muitos casais podem ver a inviabilidade de terem filhos por questões financeiras (Santos, 2015).

Mesmo aqueles casais que possuem condições financeiras estáveis podem optar por não ter filhos tendo o critério financeiro como motivação, visto que ter filhos aumentaria significativamente as despesas familiares e o casal necessitaria, ainda que apenas em partes, abrir mão da qualidade de vida, que dentre outras questões, é influenciada pela renda:

... há um tempo atrás já pensei em ter filhos, mas não tenho a intenção de sacrificar a qualidade de vida que temos. (homem, 33 anos, advogado)

\section{Satisfação conjugal}

Também buscamos, na pesquisa, compreender a satisfação conjugal dos parceiros em relação a não ter filhos e se existem efeitos sobre a satisfação conjugal quando a decisão por não ter filhos é tomada antes ou depois da união conjugal.

Nova Perspectiva Sistêmica, v. 29, n. 67, p. 56-69, agosto 2020. 
A esse respeito foi observado que sete dos casais (14 participantes) tomaram a decisão antes do início da união conjugal e três (seis participantes) após a união conjugal. No entanto, não foi identificada a influência sobre a satisfação conjugal no que concerne à tomada da decisão por não ter filhos antes ou depois do início do relacionamento, à medida que todos os casais relataram se sentirem satisfeitos com os seus relacionamentos.

Foram investigados também os efeitos sobre a satisfação conjugal no que diz respeito à decisão ser tomada primeiramente por apenas um dos cônjuges. Referente a esses aspectos, a decisão por não ter filhos foi tomada primeiramente por oito das mulheres, duas primeiramente pelos homens, e quatro casais (oito cônjuges) tomaram a decisão juntos, e duas pessoas deram respostas divergentes das dos seu cônjuge. Foi observado que dos dois casais (quatro participantes) que afirmaram terem conflitos no relacionamento conjugal, a decisão por não ter filhos foi tomada inicialmente por apenas um dos cônjuges. Dessa forma, foi possível perceber que quando a decisão não é tomada inicialmente por ambos os cônjuges, esta pode gerar conflitos.

Vale ressaltar que os casais que relataram terem conflitos relacionados à decisão asseveram que estes ocorreram no início do relacionamento. A exemplo, seguem fragmentos do relato de alguns participantes que afirmaram terem conflitos no relacionamento conjugal:

Já tivemos alguns conflitos [...] eu confesso que no início tinha dificuldade de aceitar, hoje em dia vejo que eu realmente não quero, pelo tempo escasso e por excesso de preocupação que eu não tenho interesse em ter. (homem, 40 anos, administrador)

Quando nos casamos não conversamos sobre isso, então tivemos que conversar para chegarmos a essa decisão. No início foi complicado porque eu não tinha certeza como ela. (Homem, 26 anos, frentista)

O fato de a decisão por não ter filhos ter sido tomada na maioria das vezes por mulheres sugere a subversão dos estereótipos de gênero feminino. Mas quando homens não têm filhos, isso não traz a mesma cobrança social observada quando mulheres optam pela não maternidade. Dos participantes entrevistados 16 relataram sofrer cobranças para ter filhos e discriminação por não tê-los. Nos relatos emergem uma predominância de cobranças por parte dos familiares e mulheres.

As pessoas acham que somos obrigados a sermos pais, não aceitam e não entendem essa decisão. Minhas amigas e minha mãe me cobram e eu tenho que ouvir que ser mãe é o sentido da vida. (mulher, 29 anos, dona de casa)

Já fomos excluídos de eventos para família porque o meu esposo e eu não somos considerados uma família por não ter filhos [...] Sempre comentam que vamos "pagar a língua" ou que somos muito jovens e iremos mudar de ideia. Escuto isso de muitas mulheres, parece que estão me jogando uma praga porque eu não quero ser como elas. (mulher, 24 anos, acadêmica de Nutrição)

Badinter (2011) ressalta que a mulher que decide não ter filhos dificilmente escapará da hostilidade da sociedade, por definição natalista, e do Estado, que tem múltiplos pequenos meios de punir e estigmatizar quem não cumpre seu dever, tornando tão difícil a escolha pela não maternidade a ponto de ser preciso ter uma

Nova Perspectiva Sistêmica, v. 29, n. 67, p. 56-69, agosto 2020. 
1 Para Judith Butler (2003), a performatividade diz respeito a atos repetidos, a imitações, que produzem significados sobre 0 que seria masculino e feminino como vemos atualmente. A performatividade faz com que a linearidade entre sexo, gênero e desejos e práticas sexuais heterossexuais, de tão repetidas, se tornem norma aos olhos sociais. "vontade a toda prova e um caráter inflexível" para manter esse posicionamento. Outro ponto importante é a questão de que a maternidade faz parte do projeto sexo/ gênero da norma heterossexual, portanto, quando uma mulher opta por não ser mãe, ela deixa de performatizar ${ }^{1}$ um signo heterossexual importante, o que pode lhe causar marginalização, sendo que essas cobranças teriam como função levá-la de volta à estabilidade do projeto de norma heterossexual.

No mesmo projeto heterossexual, quanto a um casal com plenas capacidades biológicas para ter filho optar por não tê-lo, isso é relativamente incompreensível, o que, segundo Silva (2016), torna difícil a aceitação e compreensão dessa decisão em nossa sociedade.

Gabriel e Dias (2011) afirmam que, apesar dos inúmeros estudos psicológicos e sociológicos sobre as diversas formas de família que existem na atualidade, ainda se costuma pensar que, para ser considerada uma família de fato, é necessário que um casal tenha filhos. $\mathrm{O}$ autor argumenta ainda que logo após o casamento, quer este seja formal ou informal, normalmente a expectativa social da chegada dos filhos inicia e a cobrança por tê-los passa a ser uma rotina, para que o casal produza o "fruto do seu amor" e torne-se finalmente uma "família completa". Logo, a norma heterossexista diz que a maternidade/paternidade é o ciclo "natural" de todo o ser humano, em especial da mulher.

Os quatro participantes que relataram não serem cobrados para ter filhos eram homossexuais. Os mesmos afirmam:

... nunca fomos cobrados, acho que a sociedade prefere assim, já que somos um casal homoafetivo por isso estamos "inaptos" para sermos pais. (homem, 55 anos, bibliotecário)

... acho que não é esperado que um casal homossexual tenha filhos, por isso ninguém nunca perguntou. (mulher, 26 anos, acadêmica de letras)

O modelo de família considerado padrão é o heterossexual. Paternidade/ maternidade de casais homossexuais fogem desse padrão. Assim, é importante pontuar que o discurso do senso comum, geralmente fundamentado nas suas concepções religiosas de base judaico-cristã, serve de base para expressões do preconceito às pessoas homossexuais, demonstrando repúdio ao casamento e à adoção, atitudes que podem ser entendidas segundo as representações sociais acerca dos homossexuais (Pereira et al., 2013).

Como descrito anteriormente, todos casais afirmam se sentirem satisfeitos com seus relacionamentos conjugais e acreditam que ter filhos não melhoraria a relação. Alguns participantes relataram que um filho traria infelicidade, pois não o desejam.

Estou satisfeita com o meu casamento, temos brigas como qualquer outro casal, mas somos felizes. Temos tempo um para o outro, somos companheiros e não precisamos de um filho para sermos felizes [...] os filhos não devem ser responsáveis pela felicidade de um casal. (mulher, 41 anos, ondontóloga)

... não posso reclamar, pois temos muita sorte de ter um ao outro [...] acredito que um relacionamento amoroso não precisa gerar filhos para ser plenamente satisfatório. Até acho que a decisão de não tê-los fortalece o casal, que vai ter que ir na contramão do sistema e focar 100\% no próprio relacionamento. (homem, 47 anos, engenheiro ambiental)

Apesar de os participantes heterossexuais serem estigmatizados pela decisão e sofrerem cobranças, eles e também os participantes homossexuais se mostraram 
satisfeitos com seus relacionamentos conjugais, relatando sentimentos de amor, companheirismo e prazer. Dessa forma, nesta pesquisa, os casais que optaram por não ter filhos possuíam outros planos que estão focados na carreira profissional, lazer, vida financeira estável.

\section{CONSIDERAÇÕES FINAIS}

Decidir não ter filhos foge do que é socialmente esperado de um casal heterossexual. Esta pesquisa sugeriu que essa decisão muitas vezes pode levar à estigmatização, que pode vir, dentre outras pessoas, por parte de mulheres que cumprem o projeto de gênero tido como natural para si, incidindo em outras mulheres que subvertem a maternidade compulsória quando escolhem não ser mães. Como relatado por uma das participantes, decidir não ter filhos é "ir na contra-mão", é estar sujeita à discriminação, críticas e até mesmo à exclusão, pois muitas vezes tais relações fogem à norma heterossexual do ciclo familiar que necessariamente pressupõe a reprodução como uma função da família para a perpetuação da espécie.

Um dos pontos discutidos na pesquisa mostra que a decisão por não ter filhos pode partir de mulheres e de homens e que vários fatores contribuem para essa decisão, como, por exemplo, o desenvolvimento profissional feminino, visto que muitas vezes pode ser requerida de mulheres a escolha entre a carreira profissional e a maternidade, mas os dados sugerem o baixo protagonismo masculino nessa decisão, considerando que a paternidade não tem a mesma força social que a maternidade. É aceitável, então, que homens não sejam pais, mas um fator encontrado pela decisão de não ter filhos para homens é a questão de ser o mantenedor da casa, algo voltado aos estereótipos de masculinidade.

No presente estudo sugerimos que casais sem filhos estavam satisfeitos com seus relacionamentos e não precisaram ser pais ou mães para se sentirem felizes dentro da relação. A decisão de não ter filhos foi atravessada por questões voltadas a classe social, renda familiar e qualidade de vida dos parceiros, com especial atenção a como a não maternidade pode direta ou indiretamente auxiliar nas possibilidades de desenvolvimento profissional da mulher que opta por não ter filhos.

Esperamos que essa pesquisa auxilie na compreensão de dinâmicas e contradições relacionais de casais sem filhos por opção, auxiliando assim terapeutas que atuam com esse público. Deixamos como sugestão a realização de mais pesquisas sobre o tema, principalmente voltado ao recorte de casais homossexuais que optam por não ter filhos, o que apareceu neste estudo, mas, devido à sua lmitação, não foi aprofundado.

\section{REFERÊNCIAS}

Bardin, L. (2016). Análise de conteúdo. Lisboa: Ed. 70.

Badinter, E. (1985). Um amor conquistado: O mito do amor materno. Rio de Janeiro: Nova Fronteira.

Badinter, E. (2011). O conflito: a mulher e a mãe. Rio de Janeiro: Record.

Beauvoil, S. (1980). O Segundo sexo - fatos e mitos. São Paulo: Difusão Européia do Livro.

Berger, P. \& Kellner, H. (1964). Casamento e construção da realidade: um exercício na microssociologia do conhecimento. Diógenes, 12(46), 1-24.

Borges, C. C. (2013). Mudanças nas trajetórias de vida e identidades de mulheres na contemporaneidade. Psicologia em Estudo, 18(1), 71-81. 
Butler, J. (2003). Problemas de gênero: feminismo e a subversão da identidade. Rio de Janeiro: Civilização Brasileira.

Caetano, C., Martins, M. S. \& Motta, R. C. (2016). Família contemporânea: estudo de casais sem filhos por opção. Pensando Famílias, 20(1), 43-56.

De Ollos, I. Y. \& Kapinus, C. A. (2002).Aging childless individuals and couples: suggestions for new directions in research. SociologicalInquiry, 72(1), 72-80.

FaleiroS, Fu, Käppler, C., Pontes, F. A. R., Silva, S. S. C., Goes, F. S. N., \& Cucick, C. D. (2016). uso de questionário online e divulgação virtual como estratégia de coleta de dados em estudos científicos. Texto \& Contexto - Enfermagem, 25(4), e3880014.

Féres-Carneiro, T. (1998). Casamento contemporâneo: o difícil convívio da individualidade com a conjugalidade. Psicologia: reflexão e crítica, 11(2), 1-10.

Féres-Carneiro, T. \& Diniz-Neto, 0. (2010). Construção e dissolução da conjugalidade: padrões relacionais. Paidéia, 20(46), 269-278.

Freiltas, W. M. F., Silva, A. T. M. C., Coelho, E. A. C, Guedes, R. N., Lucena, K. D. T., \& Costa, A. P. T. (2009). Paternidade: responsabilidade social do homem no papel de provedor. Revista de Saúde Pública, 43(1), 85-90.

Gabriel, M. R. \& Dias, A. C. G. (2011). Percepções sobre a paternidade: descrevendo a si mesmo e o próprio pai como pai. Estudos de Psicologia, 16(3), 253-261.

Gill, A. C. (2017). Como elaborar projetos de pesquisa. São Paulo: Atlas.

Grandesso, M. (2000) Sobre a reconstrução do significado: Uma análise epistemológica e hermenêutica da prática clínica. São Paulo: Casa do Psicólogo.

Heilman, M. E. \& Okimoto, T. G. (2008). Motherhood: a potential source of bias in employment decisions. Journal of Applied Psychology, 93(1), 189-195.

Hewlett, S. A. (2002). Executive women and the myth of having it all. Harvard business review, 80(4), 66-73.

Instituto Brasileiro de Geografia e Estatística - IBGE. (2010). Síntese dos indicadores sociais. Rio de Janeiro, RJ: Autor. Recuperado de https://biblioteca.ibge.gov.br/ visualizacao/livros/liv45700.pdf

Instituto Brasilleiro de Geografia e Estatística - IBGE. (2015). Síntese dos indicadores sociais. Rio de Janeiro: Autor. Recuperado de https://biblioteca.ibge.gov.br/ visualizacao/livros/liv95011.pdf

Instituto Brasileiro de Geografia e Estatística - IBGE. (2017). Síntese dos indicadores sociais. Rio de Janeiro: Autor. Recuperado de https://biblioteca.ibge.gov.br/ visualizacao/livros/liv101459.pdf

Instituto Brasileiro de Geografia e Estatística - IBGE. (2018). Síntese dos indicadores sociais. Rio de Janeiro: Autor. Recuperado de https://biblioteca.ibge.gov.br/ visualizacao/livros/liv101629.pdf

Instituto Brasilleiro de Geografia e Estatística - IBGE. esquisa nacional por amostra de domicílios: Síntese de indicadores 2009. Rio de Janeiro: Autor. Recuperado de https://biblioteca.ibge.gov.br/visualizacao/livros/liv45767.pdf

Levandowski, D. C. \& Piccinini, C. A. (2006). Expectativas e sentimentos em relação à paternidade entre adolescentes e adultos. Psicologia: teoria e pesquisa, 22(1), 17-27.

Magagnin, C. et al. (2003). Da conjugalidade à paternidade: Gavidez, ajustamento e satisfação conjugal. Aletheia, 17-18(1), 41-52.

Mattar, L. D. \& Diniz, C. S. G. (2012). Reproductive hierarchies: motherhood and inequalities in women's exercising of human rights. Interface - Comunic., Saude, Educ. 16(40), 107-119.

Moura, S. M. S. R. \& Araújo, M. F. (2004). A maternidade na história e a história dos cuidados maternos. Psicologia: ciência e profissão, 24(1), 44-55. 
Norgren, M. B. Pr, Souza, R. M., Kaslow, F, Hammerschmidt, H., \& Sharlin, S. A. (2004). Satisfação conjugal em casamentos de longa duração: uma construção possível. Estudos de Psicologia (Natal), 9(3), 575-584.

Patias, N. D. \& Buaes, C. S. (2012). "Tem que ser uma escolha da mulher”! Representações de maternidade em mulheres não-mães por opção. Psicologia \& Sociedade, 24(2), 300-306.

Pereira, C. R., Torres, A. R. R., Falcão, L., \& Pereira, A. S. (2013). O papel de representações sociais sobre a natureza da homossexualidade na oposição ao casamento civil e à adoção por famílias homoafetivas. Psicologia: Teoria e Pesquisa, 29(1), 79-89.

Priore, M. D. (2014). Histórias íntimas. São Paulo: Planeta.

Rios, M. G. \& Gomes, I. C. (2009). Estigmatização e conjugalidade em casais sem filhos por opção. Psicologia em Estudo, 14(2), 311-319.

Santos, I. C. L. (2015). Mulher solteira procura: Um estudo em torno da solteirice na representação social feminina. Polêmica, 14(1), 1-22.

Silva, F. B. S. (2016). Mulheres que optaram por não ter filhos. Monografia de especialização, Universidade Federal de Santa Catarina, Centro de Filosofia e Ciências Humanas. Pós graduação em Gênero e Diversidade na Escola, Florianópolis, SC. Recuperado de https://repositorio.ufsc.br/ handle/123456789/173769.

Somers, M. D. (1993). Uma comparação de adultos e pais voluntariamente sem filhos. Jornal of Marriage And the Family, 55(1), 643-650.

\section{INGRID MESQUITA COELHO}

Graduada em Psicologia, mestranda em Psicologia pela Universidade Federal do Pará (UFPA).

https://orcid.org/0000-0001-9723-8557

E-mail: ingridm.c@hotmail.com

\section{DANIEL CERDEIRA DE SOUZA}

Psicólogo, mestre em Psicologia e Processos Psicossociais pela Universidade Federal do Amazonas (UFAM); doutorando em Psicologia Social e Cultura pela Universidade Federal de Santa Catarina (UFSC).

https://orcid.org/0000-0002-2446-8244

E-mail: dancerdeira01@gmail.com

\section{IOLETE RIBEIRO DA SILVA}

Doutora em Psicologia pela Universidade de Brasília. Professora da Universidade Federal do Amazonas e Diretora da Faculdade de Psicologia (UFAM). Bolsista Produtividade CNPq 2. Atua no Programa de Pós-Graduação em Psicologia (PPGPSI/UFAM) e no Programa de Pós-Graduação em Educação (PPGE/ UFAM). É conselheira e Presidente do Conselho Nacional dos Direitos da Criança e Adolescente (2020).

https://orcid.org/0000-0002-9416-6866

E-mail: ioleteribeiro@ufam.edu.br 